\title{
МИРОВОЙ РЫНОК ЭЛЕКТРОТЕХНИЧЕСКОЙ ПРОДУКЦИИ: ОБЗОР СОВРЕМЕННЫХ ТЕНДЕНЦИЙ
}

\author{
(c) 2018 Левченко Лариса Владимировна \\ кандидат экономических наук, доцент \\ Самарский государственный экономический университет \\ 443090, г. Самара, ул. Советской Армии, д. 141 \\ E-mail: lvls@mail.ru \\ (c) 2018 Иванова Наталья Игоревна \\ кандидат экономических наук, доцент \\ Самарский государственный экономический университет \\ 443090, г. Самара, ул. Советской Армии, д. 141 \\ E-mail: cleotasha@rambler.ru \\ (c) 2018 Алиева Лиля Ильдаровна \\ магистрант \\ Самарский государственный экономический университет \\ 443090, г. Самара, ул. Советской Армии, д. 141 \\ E-mail: al-lilya@mail.ru
}

Актуальность темы исследования обусловлена бурным развитием электротехнической промышленности мира, в условиях глобализации, слияния и поглощения. Сложная экономическая ситуация вынуждает компании уделять особое внимание ведению внешнеэкономической деятельности, конкуренции, поиску новых рынков сбыта и эффективных стратегий управления. Развитие электротехнической промышленности, как общемировое явление в экономике и политике, набирает высокие темпы развития с усовершенствованием стандартизации, унификации и правовой основы производства электротехники. Проанализирована динамика и конъюнктура мирового рынка энергетического машиностроения, выявлены страны - и компании - лидеры данной отрасли, систематизированы факторы их функционирования в современных условиях; рассмотрены современные тенденции деятельности предприятий; исследованы проблемы и перспективы мирового рынка электротехники.

Ключевые слова: электротехническая промышленность, энергетический сектор, глобализация, интеграция, конгломераты, лидеры рынка электротехники, стандартизация, Международная электротехническая комиссия (IEC), тенденции развития рынка.

На сегодняшний день мировой рынок энергетического машиностроения оценивается в 87 млрд.долл. в год, основываясь на структурную динамику роста, годовой объем может достигнуть 110 - 115 млрд. долл. в год до 2025 г.

Мировой рынок сервиса энергетического оборудования в 2016 году составляет 31,7 млрд. долл., в том числе: LTSA (долгосрочный сервис) $47 \%$, модернизации - 20\%, полевой сервис - $24 \%$, инжиниринг - 9\% [5].

Лидерами на рынке являются корпорации Siemens (Германия), General Electric (США), Mitsubishi Heavy Industries (Япония), Shanghai Electric Power Generation Group (Китай), Schneider Electric (Франция), ПАО «Силовые машины» (Россия), ЗАО «ГК «Электрощит» - ТМ Самара» (Россия) в основном благодаря исторически сильному положению на рынке энергомашиностроения и масштабам производства.

В настоящее время отмечается прогрессирующая тенденция, направленная на поддержание и укрепление активов, инвестиционных проектов. Особо отчетливо она проявляется в международных экономических структурах, энергетических корпораций, производственных конгломератов, имеющих функциональную направленность к процессам слияния и поглощения, целью которых является структурное, эффективное, нацеленное на результат финансирования НИОКР. 
Так следствием слияния Alstom с ABB и Siemens c Westinghouse являются крупные отраслевые конгломераты, владеющие широким сегментом мирового рынка. Тенденции такого характера создают сложности в производстве и угрозы успешному функционированию российского энергетического машиностроения.

Если до слияния многие российские компании, реализовавшие себя в мировой электротехнической промышленности, имели возможность выполнять работы и услуги (сервисные, монтажные, инжиниринговые) посредством аутсорсинга, то на сегодняшний день у зарубежных производителей нет потребности в привлечении отечественных компаний-машиностроителей к работе в проектах и на производственных площадках. Такое положение российских предприятий находит свое отражение в специфике правового аспекта производства и международного сотрудничества, разобщенности российских компаний, ограниченности в поставках на внешний рынок отдельных агрегатов и функциональных узлов электростанций. Для поставки на рынок комплексного продукта, специфических источников электростанций, выполнения полного комплекса пуско-наладочных работ не все отечественные производители располагают соответствующими производственными масштабами, в следствие чего сталкиваются с рядом проблем и неустоек.

В развитых странах экологические требования и поддержка локальных производителей энергетического оборудования затрудняют конкуренцию российских производителей. Ведение бизнеса в африканских странах пока сопровождается высокими политическими и экономическими рисками за некоторым исключением является внедрение инвестиционных проектов в Тунисе, Египете, Марокко.

Автоматизация технологических процессов и вопросы энергоэффективности - это два основных тренда, которые сегодня задают вектор развития рынка электротехники. Особое внимание уделяется использованию новых материалов, развитию альтернативной энергетики и совершенствованию методов хранения энергии. Эти направления активно развиваются и находят применение в электротехнической промышленности разных стран мира. Однако их разработка требует больших инвестиций и доступа к мировому рынку компонентов. Учитывая сложность технологий, отдельно взятой компании эти задачи решить крайне сложно. Поэтому здесь единственно правильным является путь интеграции и взаимодействие в рамках совместных проектов.

В 2017 - 2018 гг. прогнозируется усиление конкурентной борьбы в мире электротехники, спровоцированной сжатием рынка, увеличением его участников. В такой ситуации будет возрастать ценность каждого крупного тендера на электронных площадках В2В и не только. В то же время мировые производители могут оказаться несколько ограниченными в поиске заказов и в продвижении своей товарной линейки. В первую очередь это может быть связано с недостатком средств, который спровоцируют некомфортные для производственных компаний условия оплаты и сбыта.

Крупные размеры, значительный капитал и масштаб производства фирм крайне немобильны на рынке, следовательно, в таких условиях для достижения наибольшей выгоды, поддержания цен и максимизации прибыли олигополистические фирмы идут на сговор между собой. Производители договариваются о взаимовыгодном сотрудничестве, заключая соглашение о разделении рынка, так называемое «картельное соглашение». Подобным объединением на арене мирового рынка электротехнической продукции является картель Phoebus.

Весомая доля в мировой электротехнической промышленности по праву принадлежит «гигантам» отрасли:

- американская корпорация General Electric (GE), основным направлением деятельности которой является электрификация всего мира. Корпорация является производителем техники и продукции в различных сферах энергетической промышленности начиная от кабелей, переходников и соединителей, заканчивая атомными реакторами, газовыми турбинами, атомными реакторами, двигателями и т.д.

На текущее время в компании трудятся более 313 тыс. человек, а чистая прибыль в среднем составляет 13 млрд. долл. в год, география присутствия более чем в 160 странах. В рейтинге Fortune по рыночной капитализации занимает 13 место в 2017 году с выручкой 12,3 млрд.долл. [14] Двумя последними крупными покупками GE были энергетический бизнес европейской компании Alstom, купленный за 10 млрд.долл. в 2015 году и покупка 62,5\% доли в нефтесервисной компании Baker Hughes за 7,5 млрд.долл. 
Инвесторы начали терять веру в компанию еще зимой 2017 года после разочаровывающих финансовых результатов. Рынок отказался от акций после того, как руководство компании под руководством Джона Фланнери, который взял на себя роль бывшего генерального директора Джеффа Иммельта сократило свою целевую прибыль и дивиденды на 50\%, потратило около 400 млрд.долл. на сделки М\&A, явно переоценив возможности рынка.

K концу 2017 года акции GE потеряли 45\% своей стоимости, и теперь они предлагают долгосрочным инвесторам возможность для инвестирования. В 2018 году ожидается дальнейшее падение прибыли еще на 25\%. Сейчас General Electric находится в начале долгого и сложного пути трансформации бизнеса. Вполне вероятно компании придется продавать недавно купленные активы, фиксируя убытки. Нельзя исключать и еще одно сокращение выплаты дивидендов, так как проблема с ликвидностью компании все еще остается напряженной.

- германский концерн Siemens AG, имеет широкий спектр функционирования и производства в области энергетического машиностроения, производства электротехники, бытовой электроники, а так же успешно реализовывается в специализированных услугах промышленности медицинского оборудования, транспорта и связи

Производственные мощности и рабочие площадки компании расположены преимущественно в странах Европейского союза, а так же в Канаде, США, Мексике - так называемой зоне НАФТА. Концерн основательно внедрил свое производство и в Китае, Бразилии, Индии, России и многих других странах. Чистая прибыль немецкого промышленного концерна Siemens AG, приходящаяся на акционеров, по итогам 2016 - 2017 финансового года возросла на 11\% и достигнула 7,18 млрд. долл. Согласно наблюдениям маркетингового агенства Kantar Millward Brown и холдинга WPP, в январе 2018 г. концерн Siemens AG успешно вошел в десятку самых дорогих немецких брендов [18].

- французская энергомашиностроительная компания Schneider Electric-является крупнейшим производитель оборудования для энергетических комплексов промышленных предприятий, объектов гражданского и жилищного строительства, имея в своем арсенале технические и научные центры, способные к поставке необходимой линейки оборудования для многих сфер производства, а также выполняя инжиниринговые и монтажные работы «под ключ». Владеет подразделениями в более чем в 100 странах, к примеру $3 \mathrm{AO}$ «ГК «Электрощит» - ТМ Самара», которое было приобретено Schneider Electric 2013 году, имеет достойные финансовые показатели и внушительные производственные мощности, не уступая иностранным конкурентам. Для Schneider Electric российский рынок был и остается одним из главных. По обороту он занимает четвертое место вслед за США, Китаем и Францией. С 2010 г. по 2016 г. - компания инвестировала в российский рынок более 1 млрд. евро, сегодня у нее в России работают пять заводов, например, в Сколково функционирует Центр научно-исследовательских и опытно-конструкторских работ по внедрению и разработке программных решений для Smart Grid. B 2017 году чистая прибыль составляет 12,57 млрд. долл.;

Электротехническая промышленность, реализовываясь на рынке посредством работы своих «локомотивов» - Германии, Японии, США и Швеции, является одной из крупнейших мировых отраслей, имеет следующие подразделения: электротехническое тяжелое промышленное машиностроение; бытовая электротехническая и кабельная промышленность.

Энергетическое машиностроение в развитых странах основывается на современной развитой научной базе, опирается на высококвалифицированные трудовые ресурсы, специализированные кадры, выбор правильного сбытового сегмента рынка, высокое качество и конкурентоспособность выпускаемой продукции. Удельный вес произведенной электротехнической продукции Schneider Electric в общем экспорте составляет более $80 \%$. Основным стимулирующим фактором в развитии этой отрасли в новых индустриальных странах является дешевизна рабочей силы, узкая специализация, основанная на выпуске и производстве трудоемкой, но технически примитивной и не всегда соответствующего качества продукции, не требующей крупномасштабных затрат.

B современной региональной структуре электротехнического машиностроительного комплекса мира следует выделить основные производственные макрорегионы: Северная и Центральную Америку зарубежная Европу, Азия и страны СНГ [6]: 
- Северная Америка, на долю которой приходится примерно одна третья стоимости, создаваемой в мировом электротехническом машиностроении, отличается лидером своего сегмента рынка - США. На долю соединенных штатов приходится почти 30\% стоимости мировой машиностроительной продукции.

- Зарубежная Европа имеет прочные конкурентные позиции на рынке электротехники, серьезные перспективы в производстве и инновациях, благодаря не успешному функционированию производственных мощностей Германии в области энергетики, но и реализации крупных экспортных поставок. Регион справедливо владеет около одной трети продукции мировой электротехники с помощью реализации на рынке Франции, Великобритании, Италии.

- Регион Восточной и Юго - Восточной Азии производит, примерно, одну четвертую продукции мирового энергомашиностроительного рынка. По праву, лидером региона является Япония - вторая машиностроительная держава в мире, прочно зарекомендовавшая себя как надежный и успешный партнер, производитель и поставщик. Имеет долю в размере $15 \%$. Отмечают и другие страны региона - Южная Корея, Китай, Сингапур, Таиланд, Индонезия, Малайзия производящие, достаточно, трудоемкую, но менее сложную продукцию, укрепляющие зарубежные сбытовые сети для реализации активной экспортной политики.

- Страны СНГ являются достаточно крупными производителями силового, кабельного, высоковольтного оборудования. Отмечены прогрессирующие позиции России в регионе, имеющей серьезные возможности для развития электротехнического производства, основываясь на научно-техническом, интеллектуальном и ресурсном потенциале. Отечественные предприятия посредством успешной реализации программы импортозамещения, основываясь на емкий внутренний рынок, имеют тенденции и перспективы в развитии, не уступая зарубежным конкурентам.

Итак, электротехническая промышленность характеризуется многоотраслевой структурой. Лидерами в производстве электротехники являются: Китай с долей продукции в экспорте $-11,2 \%$ (553 млн.долл.), США - 7,2\% (260 млн.долл.), Германия - 6\% (138 млн.долл.), Корея $-5,8 \%$ (134 млн.долл.), Япония $-4,3 \%$ (98 млн.долл.) [15].
Продукция электротехнической промышленности востребована во всех отраслях экономики и социальной сферы. Это высокотехнологичный рынок, развитие которого является приоритетным для экономики любой страны.

Серьезная и масштабная модернизация электротехнической отрасли только предстоит, но в последние годы заметен ряд позитивных тенденций и перспектив, обусловленных желанием производителей занять свою достойную нишу на рынке, расширив и укрепив сбытовую стратегию и экспортную структуру.

Имея структуру горизонтальной функциональной интеграции, мировая электротехническая отрасль находится под существенным давлением с одной стороны, партнеров - поставщиков сырья, товаров субститутов, вспомогательного оборудования, а с другой стороны - основного потребительского сегмента.

Итогом комплексного воздействия противоположных структур определяет и формирует стратегию дальнейшего функционального развития отрасли в целом и заставляет производителей быть более гибкими, быстро реагировать на изменения и принимать стратегически верные решения. Следовательно, действующие пять сил Портера формируют не только высокую конкуренцию в электротехнической отрасли, но и задают курс основным тенденциям рынка [10]:

1. Создание представительств, филиалов и дочерних предприятий. Лидеры рынка, так называемые, транснациональные корпорации инвестируют активы в открытие филиалов и представительств в различных странах мира, расширяя сбытовую сеть, стимулируя развитие национальной экономики, улучшая качество продукции и создавая рабочие места;

2. Развитие российского и зарубежного производства, сочетание отечественной и импортной продукции. В России базовым нормативно-правовым актом является «Программа импортозамещения оборудования, технологий, материалов и систем в ПАО «ФСК ЕЭС» на период 2015-2019 годы». В соответствии с Энергетической стратегией РФ на период до 2030 года, политикой взаимодействия с обществом, потребителями и органами власти ПАО «Россети», планируется стимулирование развития производства и увеличение доли отечественного электротехнического оборудования (основного и вторичного) в закупках до 95\%;

3. Наблюдается заинтересованность миро- 
выми компаниями производство в сфере электротехники. Посредством охвата отрасли находит свое отражение усиленная конкурентная борьба, итогом которой является: активизация инновационного процесса, гибкое приспособление и адаптация к изменениям спроса, высокая производительность труда и надлежащее качество продукции;

4. Создание новых производственно-торговых предприятий, основной вид деятельности которых носит характер сборки качественных электрических щитов, изготовление кабельных каналов, низковольтного, высоковольтного оборудования, а также производство уникального дорогостоящего оборудования для энергохолдингов;

5. Обосновано и успешное внедрение тенденции к увеличению оптовых скидок, выгодных предложений по реализации сервисных и инжиниринговых услуг, привлечение дистрибьютеров и дилеров, мотивируя их выгодными условиями долгосрочного сотрудничества, исключая барьеры торговли, демпинг цен и недобросовестную конкуренцию.

Основными рыночными тенденциями сегодня являются курс на энергоэффективность и повышение безопасности эксплуатации электротехнического оборудования и в целом профессиональных электроизмерительных приборов.

Ведение активной политики энергосбережения, посредством направления инвестиций и национального дохода в русло рационального расходования, использование энергосберегающих технологий во всех отраслях экономики, внедрение программ по очистке окружающей среды и сокращение выбросов в сточные воды и атмосферу, развитие и поддержание международной торговли являются приоритетными и актуальными задачами предприятий при должной поддержке государства.

Производители начинают уделять всё большее внимание вопросам безопасности электрооборудования, ведь его неисправность является одной из самых распространенных причин возникновения пожаров.

Еще одним рыночным трендом становится широкое внедрение сервисной модели взаимоотношений «360о» между вендором (производитель) и конечным заказчиком. Это означает, что сегодня крупнейшие поставщики электрооборудования стремятся к реализации комплексных проектов в интересах клиентов «под ключ», решая конкретные инфраструктурные проблемы и предоставляя гарантийное обслуживание на протяжении всего жизненного цикла устройств и решений.

Предприятия стремятся стать лидерами во внедрении новых идей, проектов и разработок, уделяя внимание современным технологиям в менеджменте, обеспечивая полный жизненный цикл продукции как на внутреннем, так и на внешнем рынках, сокращая сроки производства, минимизируя затраты на него. Необходимо уделять внимание соотношению цены и качества продукции, внедряя стратегии менеджмента и ориентируясь на современные условия реализации товара в экономике

Как и любая отрасль промышленности, сфера электротехники имеет свои сложности и проблемы.

Глобализация мирового рынка, характеризующаяся стиранием границ на пути свободного перемещения людей, товаров и услуг, капитала и информации, требует перехода стран на единые стандарты. Одной из основных проблем электротехнической промышленности является производство электротехнического оборудования не в соответствии с международными стандартами, нормами, разработанными и общепринятыми Международной организацией стандартизации (ISO) и Международной электротехнической комиссией (IEC). Электротехническая продукция, электроизмерительные приборы и установки нацелены на обеспечение электробезопасности и предотвращения аварийных ситуаций, следовательно необходимо наладить производство в соответствии с мировыми требованиями и стандартами.

Главной целью принятия Федерального закона РФ «О техническом регулировании» от 27.12.2002 N184 - Ф3 является процесс синхронизации российских стандартов и сертификатов соответствия с требованиями и нормативами Всемирной торговой организации по отношению к техническим барьерам в торговле.

Характерной особенностью стандартизации отечественного производства электротехники является излишние бюрократические требования. Процедура получения сертификатов соответствия, надлежащих лицензий и деклараций достаточно затратный для компании - производителя, а продолжительный срок рассмотрения документов, проведения метрологических ис- 
пытаний и исследований замедляет поступление на рынок нового товара, растут издержки производства, усложняется деятельность организации.

Недостаточная гармонизация международных и национальных стандартов, проблема в их соответствии и глобальном признании ведут к удорожанию продукции, замедлению обмена технологиями, развитию научно-технического прогресса и международной торговли.

Проблема коррумпированности стандартизации, нелегальная выдача сертификатов - соответствия, деклараций присуще не только электротехническому производству, но и другим отраслях промышленности. Компании-посредники в области метрологии и измерений, осуществляющие свою деятельность не всегда по Закону, нанося существенный отпечаток не только на производителе, но и на конечном потребителе. Работа с электротехническим оборудованием, не имеющим соответствия стандартам, может привести к несчастным случаям на производстве, так как их испытания и производство были проведены некорректно. В целях недопущения возникновения рисков, связанных с причинением вреда жизни и здоровью человека, имуществу, окружающей среде, предупреждения действий, вводящих в заблуждение потребителей, Федеральная таможенная служба России совместно с Росаккредитацией приняли меры по проведению анализа контроля таможенных операций, связанных с ввозом в Россию продукции, подлежащей проведению исследований и испытаний.

Существует проблема недобросовестной конкуренции в олигополистической структуре рынка электротехники, которая особенно актуальна для сегмента данной продукции. Некоторые компании добиваются уменьшения стоимости своих решений за счет ухудшения качества, что крайне опасно, т.к. на рынок попадает продукция, которая не отвечает заявленным характеристикам и может привести к возникновению чрезвычайных ситуаций, к примеру, в России этому уделяться всё больше внимания и уже создана целая система сбора информации о фальсификате.

Одной из наиболее важных проблем является наличие демпинга цен в международных и государственных тендерах, т.е. метод искусственного занижения цен на товары или услуги. Цель всегда одна - завоевать как мож- но большее пространство на рынках, естественно, внешних. Демпинг также один из самых распространенных сегодня способов борьбы с конкурентами. Но в этом случае он приводит е международной дискриминации цен. Иногда он порождает собой коррупционные схемы торговли.

Международный экономический кризис 2008 года повлек за собой серьезные проблемы для многих сфер промышленности и бизнеса. Стагнация экономического сектора, снижение спроса отразились и на производстве электротехнических предприятий.

Электротехническая промышленность в экономике любого государства играет важную роль в обеспечении высоких темпов роста строительства объектов недвижимости, производственных сооружений, развитии деятельности электроэнергетики, тесно взаимодействуя и дополняя различные отрасли промышленности

Введение санкций в 2014 г. повлекло за собой весьма серьезные последствия для экономики страны, которые, прежде всего, выражаются в резком снижении взаимодействий на мировом рынке:

- резко падает экспорт - отечественные предприятия теряют крупные зарубежные рынки сбыта, что влечет за собой сокращение доходов и производственного оборота в целом, следовательно и снижение налоговых отчислений;

- сокращается импорт - при торговом эмбарго бизнесмены зачастую не могут приобрести импортное сырье и расходные материалы для производства, аналогов которых в стране нет. В подобных ситуациях предприятия вынуждены приостановить работу, быть в стадии ликвидации, а позже и вовсе признать себя банкротами.

Несомненно, санкции сказываются и на уровне жизни населения в стране, подвергшейся изоляции - рост уровня безработицы, снижение прибыльности предприятий и валовых показателей производства, рост недоверия правительству страны. В то время как доходы предприятий снижаются, источники пополнения капитала исчезают, снижается и курс государственной валюты, что сказывается на покупательской способности.

Внешние и внутренние проблемы производства электротехнических предприятий [8].

Внешние проблемы мировых производителей (товаров и услуг) электротехнической про- 
мышленности:

- Технологические проблемы. Состояние экономики имеет колоссальное давление на развитие электросетевого комплекса. Существующие обстоятельства и состояние рынка усложняют развитие, приращение объектов, их модернизацию, внедрение новых технологий;

- Административные проблемы. При реализации инвестиционных программ и стратегий, производстве нового оборудования или же поставки его за рубеж субъекты рынка электротехники зачастую сталкиваются с проблемами согласования (внутреннего и внешнего), стандартизации продукции согласно действующим нормативам и оформления надлежащей документации. Все противоречия имеют отражение как во временном, так и денежном выражении, что в свою очередь существенно влияет на удорожание товара, работ или услуги;

- Конъюнктурные проблемы. На рынке зачастую встречаются идентичные, схожие по технологическим характеристикам товары разных производителей электротехники, в связи с чем возникает острая необходимость ведения честной конкурентной борьбы, основанной на улучшении технических параметров, предложения выгодных условий поставок, не ущемляя права других производителей.

Внутренние проблемы предприятий электротехнической промышленности:

- Имидж. Имидж компаний складывается, главным образом, из времени функционирования, истории становления на мировом рынке и модернизации функционирования, а не из потребительских объективных характеристик. Такие бренды электроизмерительного оборудования, как Siemens (Германи), Fluke (США), Schneider Electric (Франция), Amprobe (США), Mitsubishi Electric (Япония) заслужили спрос и доверие среди потребителей благодаря качеству, проверенному временем, долговечностью и функционированием приборов;

- Квалификация персонала. Зачастую, зарубежные компании предоставляя наиболее выгодные условия труда мотивируют к эмиграции квалифицированных специалистов и научного кадрового состава. Так называемая проблема «утечки умом» является достаточно актуальной не только для производственных отечественных предприятий, но и для мировой торговли в целом;

- Качество и иена продукции. Соотношение цены и качества продукции являются серьезным вектором, побуждающим к спросу. Проблемы негибкой ценовой политики, поддержание надлежащего качества продукта и сложности реструктуризации производственного процесса создают ряд проблем, с которыми вынуждены столкнутся предприятия энергосетевого комплекса;

- Сбытовая политика. Сбытовая политика компании тесно взаимодействует со способностью к внедрению новшеств, применением актуального промышленного маркетинга.

Деятельность электротехнических предприятий сопровождается загрязнением среды обитания токсичными поллютантами, образованием отходов и необходимостью утилизации вышедшие из строя продукции (изделий, приборов и т.п.). Общие выбросы в атмосферу специализированного завода по производству электрооборудования составляют первые сотни тысяч тонн в год, из которых более 90-95\% приходится на долю газообразных и жидких веществ.

Следует отметить, что большинство вышедших из строя электротехнических изделий не утилизируются и поступают в отходы потребления, что обусловливает потерю ценных компонентов и определяет существенную эмиссию в среду обитания токсичных поллютантов. Для разработки стратегии и тактики борьбы с опасными отходами особое значение имеет документ, разработанный на конференции странучастниц Базельской конвенции, состоявшейся в декабре 1992 г. в Уругвае, в котором обозначены основные вопросы, адресованные к производителям, экспортерам и импортерам отходов или к тем, кто занимается депонированием отходов.

Проанализировав тенденции производства электротехники, а также сложности и проблемы, связанные с производством можно сделать вывод, что в 2018 г. и в следующие несколько лет ожидается рост потребности в энергоэффективных и высокоточных измерительных приборах, которые обеспечивают эффективную и безопасную работу предприятий различных отраслей посредством привлечения реальных инвестиционных программ, минимизации затрат на производство, повышение качества выпускаемого оборудования согласно действующим нормативам и стандартам.

Ожидается, что мировой рынок этой продукции достигнет прогнозного показателя в 54,2 млрд. долл. США к 2021 году. 
Согласно прогнозу Минэкономразвития (МЭР), в 2019 году производство электрооборудования, электронного и оптического оборудования в сравнении с 2015-м годом вырастет на 8,5\%. В этой связи, как полагают эксперты IndexBox, производство трансформаторов в 2016 - 2019 гг. будет увеличиваться в среднем на 2,5\% в год.
По данным, приведенным в обзоре Lucintel, в течение 2016-2021 гг. совокупный среднегодовой темп роста мирового рынка электротехнического оборудования для электролабораторий будет составлять $6,3 \%$, в сравнении, на сегодняшний день объем мирового рынка данного оборудования составляет 49,1 млрд. долл.

\section{Библиографический список}

1. Федеральный закон «Об электроэнергетике» от 26.03.2003 N35 - Ф3 (ред. от 29.07.2017);

2. Приказ Министерства промышленности и торговли Российской Федерации «Об утверждении Стратегии развития энергомашиностроения Российской Федерации на 2010 - 2020 годы и на перспективу до 2030 года» от 22.02.2011 N206;

3. Баринов В.А., Исаев В.А. Направления развития электроэнергетики и единой национальной электрической сети России с учетом долгосрочной перспективы // Электротехническая промышленность. 2017. № 1. С.1213 ;

4. Доклад о целях и задачах Минпромторга России на 2017 год и основных результатах деятельности за 2016 год. Министерство промышленности и торговли Российской Федерации // Минпромторг России. 24.042017. C.102-104;

5. Иванова Ж.В. Электротехническое производство: зарождение перспективы становления социально ответственного бизнеса на рынке электротехнической продукции // Экономика машиностроительной промышленности. 2017. N6, вып. 2. С.59;

6. Левченко Л.В., Иванова Н.И. Теоретическое обоснование предпосылок и диверсификации сфер международной специализации России // Экономические науки. 2015. № 4 (125). С.7;

7. Лисин Е.М. Совершенствование методологии анализа энергоемкости энергосистем территориальных образований // Экономические науки. 2018. № 7 (164). С.41;

8. Лозенко В.Н., Михеев Д.В., Сухарева Е.В., Шиндина Т.А. Динамика показателей энергопотребления и энергоэффективности российских промышленный предприятий // Экономические науки. 2018. № 8 (165). С.38;

9. Матвеев Е.И. Глобальная энергетика на рубеже 2017 г.: борьба за ресурсы, обострение конкуренции // Российский внешнеэкономический вестник. «Бурение и Нефть».2016. № 1. С.41;

10. Новиков А.А., Эльбакян А.М. Повышение инвестиционной привлекательности электроэнергетической отрасли Российской Федерации // Экономические науки. 2016. № 10 (143). С.29;

11. Рукина Е.И., Шувалова Д.Г. Влияние величины трансакционных издержек на организационную структуру энергокомпании // Экономические науки. 2017. № 12 (157). С.37;

12. Федяков И.В. Аппаратура электрическая. Внешняя торговля РФ по итогам 2016 - 1-го полугодия 2017 года // Электротехнический рынок. 2017, № 5-6 Сентябрь - Декабрь. С.72;

13. Хансевяров Р.И. Теоретические аспекты управления инновационным развитием энергетического комплекса Российской Федерации // Экономические науки. 2016. № 4 (137). С.60;

14. Журнал Fortune. Издательство Тіme Inc. [Электронный ресурс]. - Режим доступа: http:/fortune.com/ fortune500/general-electric/ (дата обращения: 09.09.2018);

15. International Trade Centre (ITC). Международный торговый центр (МТц) [Электронный ресурс]. - Режим доступа: https://www.trademap.org/Country_SelProduct_TS.aspx (дата обращения: 07.09.2018);

16. Редакция портала «РусКабель». [Электронный ресурс]. - Режим доступа: https://www.ruscable.ru/article/ energy/ (дата обращения: 05.09.2018);

17. Статистический Ежегодник мировой энергетики Enerdata - 2018. [Электронный ресурс]. - Режим доступа: https://yearbook.enerdata.ru/electricity/electricity-domestic-consumption-data.html (дата обращения: 01.09.2018);

18. Электротехнический интернет-портал Еlec. [Электронный ресурс]. - Режим доступа: https://www.elec.ru/ news/2017/11/09/simens-ag-podvel-itogi-2017-finansovogo-goda.html] (дата обращения: 01.09.2018);

19. Коета: Мировая и региональная статистика, национальные данные, карты и рейтинги. [Электронный ресурс]. - Режим доступа: https://knoema.ru/atlas/topics/Энергетика/Электроэнергия/Чистая-выработка-электроэнергии (дата обращения: 01.09.2018). 